\title{
Study on Optimization of Biological Experiment Teaching in Universities
}

\author{
Rui Huang \\ Aba Teachers University
}

Keywords: Universities; Biological experiment teaching; Optimization study

\begin{abstract}
This study is based on the biological experiment teaching in universities' present situation, discussed the relevant problems of biological experiment teaching in universities, and combined with the future development direction of biological experiment teaching in universities of our country, summarized several biological experiment teaching optimization strategies to provide a reference for future biology experiment teaching in universities in china.
\end{abstract}

\section{Introduction}

Biology is a natural science based on experiments, especially in university education, through concrete experiment teaching, it can help students in universities acquire biology and biology experiment ability and team spirit exercise.[1]In the end of last century, the State Council promulgated the "Decision on deepening education reform and promoting quality education" which requires the strengthening of University Students' experimental ability.[2]However, recent research shows that there are fewer teaching hours on biological experiment teaching in universities. [3]For the possible biological experiment teaching in colleges, educators should pay attention and carry out education and teaching activities in accordance with the concept of innovation enhancing the degree of attention to practice teaching, optimize the teaching mode and evaluation system to enhance the quality of biological experiment teaching in universities to explore [4].

\section{Analysis of Problems on Biological Experiment Teaching in Universities}

Teaching Content Is not Perfect and Lack of Class Hour. In the present stage, almost biological experiments are simple verification experiments which are difficult to reach the basic purpose of experimental teaching so that students can understand that their experiments why do so with the relevant theoretical knowledge, in teaching content also tend to mature research and technology, backward and obsolete teaching content with a lot of knowledge, and experimental methods have already been replaced with new technology, which resulted in the waste of resources and time. In addition, many biological experiments are time-consuming and boring content combined with the university teachers in the long time before the experiment to explain and demonstrate, not only let the students do the experiment with low interest, and it also occupy a lot of time leading to the real important link, namely the student operation link time reduced. However, in the school arrangements for the class for biological experiment teaching arrangements are usually less in the face of experimental operation which is complicated, time-consuming, pretreatment that need to arrange equipment debugging time-consuming experiment, students and teachers are the fool mood, eventually led to the students do not understand, and experimental theory and experimental operation cannot get enough exercise, but depends entirely on the teacher asked to do, and this situation not only waste a lot of time, but also cause the students unconsciously develop on the bad scholarship.

Pay too much Attention to the Study of Classroom Theory, Lack of Talents and Funds. No matter what the subject, study the basic theory of knowledge is the basis for the experiment, this is no doubt, but the theoretical knowledge of the learning purpose is in order to discover a problem, then through the experiment to solve the problem. Now, many universities pay too much attention to learning theory class, not only in the course of learning theory and the experiment teaching of the two modules of the class arrangement are not reasonable, but also in the experimental teaching for teachers is dismissive attitude on this problem which also prevalent in many of the humanities and 
social science disciplines that is now in the universities of our country with large scale expansion, and the focus on lack of talent and capital, experimental courses need to have experience and ability of the excellent teachers' guide, which means a collocation advanced equipment and raw materials, a wide range of enrollment in Colleges and universities, so many subjects in the absence of excellent teachers and advanced instruments and materials under the condition of the blind establishment, will only lead to the teaching quality of the students cannot reach the real expectations.

There Is no Scientific Experimental Teaching Evaluation System. University's experiment teaching evaluation system is not scientific, students' achievement is decided by the subjective judgment of substitute teacher, and in scores of the arrangement is usually that the theory exam accounted for eighty percent or even ninety, experimental courses accounted for only twenty percent or even less than ten percent, which cause the students do not pay attention to the biological experiment course. [5]In addition, most of the teachers get score through the biological experiment report, but the students do not seriously test and they can only copy textbooks or experimental materials with modifying experimental results freely, and the purpose is to get a high score, but for the true knowledge and do not pay attention to it thinking operation quality does not matter, as long as the good experiment report can get high scores, even the experiment report had only a thousand words, while so many students write thousands of words, and some teachers also believes that this is the experiment report with learning attitude and performance, which not only let students wasting a lot of time to write the report, but ignore the fundamental learning experiment course.

\section{Optimization Method of Biological Experiment Teaching in Universities}

Theory Connected with Practice. In the new period, university should optimize the teaching process and the teaching content, which can be realized through biology experiment teaching. No matter what the subject, study the basic theory of knowledge is the basis for the experiment, this is no doubt, but the purpose of studying the theoretical knowledge is to further find out problems and then solve the problem by experiment. In the study, the theory and practice of biology teaching in biology teaching is the need of combining the teaching of biological theory course allows students to deepen the understanding of experimental course, biological experiment teaching and make students better use of biological knowledge. Therefore, the university should pay more attention to the practice of biological teaching, not only to make reasonable arrangements for curriculum theory learning and experiment teaching of the two modules of the class, but also to change the attitude of teachers for experimental teaching of contempt, and increase personnel and funds to regards the improvement of students' practical ability.

Change the Teaching Mode. Firstly, in the face of the teaching contents of experimental teaching, teachers should introduce as possible the new technology, new methods to reduce the waste of resource and time. secondly, to change the teaching pattern of experimental classes, taken after the first school teaching mode, mobilize the enthusiasm of the students, no longer step-by-step, but to enhance students' initiative clearly, and the purpose of the experimental teaching is to make students grasp the operation method of biological experiment, let students understand the basic theory of the experiment, get the ability to exercise the experimental operation, to prevent the occurrence depends entirely on the phenomenon of teachers cultivating students' subjective initiative to enable students to develop the rigorous academic attitude. Teachers can also carry out cooperative learning in the process of experimental teaching and carry out independent inquiry learning to create problem situation, then make students' participation experience and other teaching models to stimulate students' interest. For example, the protein content of determination, teachers can choose Coomassie brilliant blue method, Biuret method and Folin phenol method by allowing students to choose different materials or different methods, found their own reasons to solve their own problems. This can also be opened in different ways of supporting the experimental course, and [6] rich content of the experiment to stimulate students' interest.

Perfect Teaching Evaluation. Unscientific evaluation of college experiment teaching system limits the progress of experimental teaching in universities, teachers should start from the learning 
situation, and teaching contents are appropriate to expand to let the student achievement not be entirely determined by the substitute teacher, which not only should be combined with the actual situation of the students, but also to improve the percentage of course grade in the arrangement, let the students pay attention to biological experiment course. At the time of teaching evaluation, to avoid most of the teachers get score through the biological experiment report; they can examine the practical ability of students in biological experiment, or is subject to the student's research results and other research results to score. In short, as long as the students can reflect the ability of biological experiments can be incorporated into the evaluation system.

Standardize the Form of Experimental Report, Strengthen the Experimental Assessment. The format of the experimental report can urge students to better complete the task of curriculum. The experimental report can be divided into three levels according to the requirements, which means an overview of the part, the experimental records, analysis and discussion. The overview section can include the purpose of the experiment, experimental principle, experimental procedure and experimental. And records may include experimental phenomena, experimental data records, cultivate students rigorous and realistic scientific attitude is the focus of this phase. While analysis and discussion can include experimental results and discussion, abnormal phenomena appear in the experiment, and experiment should pay attention to this matter and on the recommendations for improvement. In this part, the students are asked to discuss the experimental phenomenon and the result and the existing problems, and to analyze the results and to express their own opinions. The lab report is divided according to the requirements into overview, experimental records, analysis and discussion, this format can promote the students' understanding and training students' creative thinking capacity, help students to improve university industry knowledge to improve the knowledge structure.

To strengthen the evaluation of the experimental results, to promote student learning, so that students can attach importance to the experiment, the careful operation of the experiment, and further enhance the students' comprehensive quality of biological experiments. The examination of the results of the experiment mainly includes theoretical knowledge, comprehensive application ability, experimental skills and so on. Effectively strengthen the assessment of biological experiments, teachers should be able to establish a set of accurate evaluation of the basic experimental skills of students and the innovative ability, comprehensive quality evaluation system. The experiment report based on the results of analysis, discussion, writing form, experiment explanation, attention to matters such as assessment, plus the experimental class attendance, preparation process, operation and other points. The importance of biological experiments urged the students to change learning attitude into not only pay attention to the theory, but also practice, at the same time, improve the learning environment of students, let students master the basic skills of biological knowledge and biological experiment study of the operation, and to improve teaching quality of biology course.

\section{Conclusion}

At the end of 90s, the State Council issued “"Decision on deepening education reform and promoting quality education" for strengthening college students' experimental ability, with the continuous progress of the teaching level, put forward higher requirements for biological experiment teaching in universities. The biological experiment teaching in university is known as the "fundamental" in biology teaching which can improve the quality of biology teaching, improve the students' basic knowledge of the use of a variety of advantages. While university's teaching now faces the problems such as biological experiment teaching content is not perfect, lack of class, too much emphasis on the theory of classroom learning, lack of talent and capital, experimental teaching scientific evaluation system and so on. With the further improvement of the teaching level of universities, the future development of biological experiment teaching in universities will become better and better. 


\section{References}

[1] Liu Enshan. Biological teaching theory (Second Edition) [M]. Beijing: Higher Education Press, 153-154. 2009:

[2] The CPC Central Committee and the State Council on deepening education reform and fully promoting quality education [J]. Higher education and economy, 1999:13.

[3] Ji Lili. Break through the routine development of biology experiment teaching in senior high school [J]. Journal of Jiangsu Institute of Education (NATURAL SCIENCE EDITION), 2010, 05: 6-8.

[4] Yan Guoguang. Problems and Countermeasures of the biological experiment teaching on science [J].Study magazine, 2016, 05:26.

[5] Zhang Jianyun, Chen hotpink. Problems and optimization measures of experimental teaching of Biochemistry [J]. Modern agricultural science and technology, 2011, 03: 44-45.

[6] Cai Yan, Wu Shun. The practice and exploration of biochemistry experimental teaching reform [J].Guide of Technology Innovation, 2010, 27: 148. 